\title{
Microstructure Characterization of Laser-Welded Nb-Microalloyed Silicon-Aluminum TRIP Steel
}

\author{
A. Grajcar, M. Różański, S. Stano, and A. Kowalski
}

\author{
(Submitted March 16, 2014; in revised form May 26, 2014; published online June 25, 2014)
}

\begin{abstract}
This work presents the results of a microstructural characterization of welds in Nb-microalloyed TRIP steel with silicon partially replaced by aluminum. Tests of laser welding of thermomechanically processed sheet samples were carried out using keyhole welding and a solid-state laser. Welding penetration tests were conducted for heat input values between 0.037 and $0.048 \mathrm{~kJ} / \mathrm{mm}$. Identification of different microstructural constituents was carried out using light microscopy and scanning electron microscopy in the fusion zone (FZ), heat-affected zone (HAZ), and base metal. Special focus was put on the effect of cooling conditions on the stabilization of retained austenite in different zones. The intercritical, fine-grained, and coarse-grained regions of the HAZ were identified. It was determined that enriching austenite with carbon in the intercritical HAZ stabilizes this phase at a level close to the base metal, i.e., a $15 \%$ volume fraction. Despite a high cooling rate in the FZ and HAZ, interlath retained austenite is also present in these zones. The research involved microhardness measurements and characterizing non-metallic inclusions formed in the fusion zone. A good correlation between microstructures formed in different weld regions and microhardness results was obtained.
\end{abstract}

Keywords HAZ, laser welding, microhardness, non-metallic inclusions, retained austenite, TRIP steel

\section{Introduction}

The increasing demands of the automotive industry for materials with rigorously specified mechanical and technological properties have resulted in the development of new alloys combining high strength, ductility, and formability. In the recent decade, the greatest technological progress in the automotive industry has been made in the development and production of advanced high-strength steels (AHSS). These have allowed reducing the weight of the car structure with a simultaneous increase in the passive safety of the vehicle's users. Reduction of the car weight is directly connected with the complex replacement of mild steels by AHSS and with using modern methods of forming sheets combined with highly efficient processes of joining them. AHSS include multiphase microstructure steels such as Dual Phase (DP), Complex Phase (CP), and Transformation-Induced Plasticity (TRIP). The high strength and plasticity of AHSS can be ascribed to their multiphase microstructure and high capability of work hardening during forming (Ref 1-4).

Increasing the efficiency of welding processes is obtained by a very high rate of heating of the elements up to their melting point and by a high cooling rate. Presently, the most commonly

A. Grajcar and A. Kowalski, Institute of Engineering Materials and Biomaterials, Silesian University of Technology, 18a Konarskiego Street, 44-100 Gliwice, Poland; and M. Różański and S. Stano, Institute of Welding, 16-18 Bl. Czesława Street, 44-100 Gliwice, Poland. Contact e-mail: adam.grajcar@polsl.pl.

applied method of joining car body steel elements is resistance spot welding (Ref 4-8). The basic limitations of this method include the necessity for using a high-pressure force which causes frequent surface deformations (decreases aesthetics) and ensuring proper surface quality in the point of contact between the electrodes and the elements being welded as well as the necessity for providing double-sided access to the elements being welded. Additional limitations include the necessity for proper positioning of welds in relation to one another and to the edges of elements being welded (Ref 8-10).

Significant progress in laser technologies has resulted in partial replacement of resistance welding with different laser beam welding methods. Laser beam welding offers a unique combination of high speed, precision, and low weld distortion when compared with resistance spot welding (Ref 9-11). Joining AHSS does not require using additional technological equipment as compared to other automotive steel grades. However, due to the increased concentration of carbon (from 0.1 to $0.3 \%)$ and alloying elements $(\mathrm{Mn}, \mathrm{Si}, \mathrm{Al}, \mathrm{Cr}$, and $\mathrm{Mo})$ in comparison with mild steels and high-strength low-alloy (HSLA) steels, joining AHSS requires additional treatment procedures and a modification of applied welding parameters.

The major technological problem during resistance welding and laser welding is the joints' susceptibility to cold cracking due to high cooling rates and the resulting high hardness. The typical problem is the occurrence of cracks in the joint plane caused by an increased content of $\mathrm{C}$ and alloying elements responsible for the AHSS' tendency to develop martensitic microstructures (Ref 5-8). The hardness of DP steel (in HAZ) is usually below $400 \mathrm{HV}$ (Ref 12), whereas in TRIP steels it is between 400 and $550 \mathrm{HV}$, depending on the carbon content in the steel (Ref 5, 7, 13). Traint et al. (Ref 4) reported that the weldability lobe of resistance-welded TRIP steels is shifted to a lower welding current, which is caused by a higher electrical resistance of TRIP steels. They also found that for these steels a 
low $\mathrm{P}$ content is a key point to ensure acceptable spot weldability in terms of plug failure after destructive testing.

The highest hardness is obtained in TRIP steels with an addition of $\mathrm{Si}(\operatorname{Ref} 4,5)$. The hardenability and hardness of the steels decrease after replacing silicon with aluminum. Unfortunately, a problem is the significant amount of non-metallic inclusions in the fusion zone. Moreover, there is the risk of obtaining a soft zone near the fusion line as a result of the excessive stabilization of ferrite (Ref 14,15$)$. The problem can be solved to some extent using TRIP steels with silicon partially replaced by aluminum, where the total concentration of these elements should not be lower than $1.5 \mathrm{wt} \%$ due to the stabilization of retained austenite (Ref 2, 4). In previous research, Grajcar et al. (Ref 13) carried out laser welding of Nbmicroalloyed Si-Al TRIP steel sheets within a heat input range from 0.037 to $0.053 \mathrm{~kJ} / \mathrm{mm}$. It was found that in order to avoid excessive grain growth, the heat input value should be limited to about $0.045 \mathrm{~kJ} / \mathrm{mm}$. Such an approach guarantees that goodquality welds will be obtained, i.e., without undercuts, porosity, and excessive metal evaporation.

The aim of the current research is a microstructural characterization of laser welds in thermomechanically processed $\mathrm{Si}-\mathrm{Al}$ high-strength steel containing $\mathrm{Nb}$ and $\mathrm{Ti}$ microadditions.

\section{Experimental Procedure}

The work focuses on the microstructural characteristics of a laser-welded 2-mm-thick TRIP steel sheet containing $0.24 \% \mathrm{C}$, $1.55 \% \mathrm{Mn}, 0.87 \% \mathrm{Si}, 0.4 \% \mathrm{Al}, 0.004 \% \mathrm{~S}, 0.01 \% \mathrm{P}$, and $0.0028 \%$ N. Partial replacement of Si by Al results in decreased strength of the steel. In order to compensate for this decrease in strength it was necessary to use microadditions of $\mathrm{Nb}(0.03 \%)$ and $\mathrm{Ti}(0.023 \%)$. By adding them we aimed at grain refinement and precipitation hardening of the steel. Samples were obtained after thermomechanical rolling as described in (Ref 2), during which $\mathrm{Nb}$ and $\mathrm{Ti}$ form dispersive carbonitrides. A major step for the stabilization of retained austenite (a crucial structural constituent of TRIP steels) was isothermal holding of the samples at $350{ }^{\circ} \mathrm{C}$ for $600 \mathrm{~s}$.

Tests on laser-welded sections of steel sheets were carried out using the keyhole welding technique with a solid-state laser, integrated with a robotized laser treatment system (Ref 13). This station meets the requirements for advanced industrial stations and is equipped with the TruDisk 12002 - solid-state laser type $\mathrm{Yb}$ :YAG. Its maximum power is $12 \mathrm{~kW}$ and the quality of the laser beam designated by the BPP parameter is $\leq 8 \mathrm{~mm}$ mrad. The CFO welding head is connected to a laser source by means of an optical fiber $200 \mu \mathrm{m}$ in diameter and a focusing lens with a focal length of fog $=300 \mathrm{~mm}$. The laser beam focus diameter was $300 \mu \mathrm{m}$.

To ensure precise positioning of the laser beam on the surface subjected to welding, the sheet was fixed by eccentric clamps to a table which was an integral part of the station. Three welding tests were carried out using various parameters. The beam power was $4 \mathrm{~kW}$ and the welding rate was changed to obtain the following heat input values: $0.037,0.043$, and $0.048 \mathrm{~kJ} / \mathrm{mm}$. The tests were carried out in an air atmosphere. After the welding tests the samples were cut in a plane perpendicular to the penetration axis and prepared for microhardness testing and for microscopic examination on the cross sections of penetrations.
In order to analyze in detail the microstructure in different zones (fusion zone-FZ, heat-affected zone-HAZ, transitional zone-TZ, and base metal-BM) and, especially, in order to identify retained austenite, it was necessary to use combined methods of light microscopy (LM) and scanning electron microscopy (SEM). Non-metallic inclusions were revealed on polished samples, whereas etching in $3 \%$ nital and $10 \%$ aqueous solution of sodium metabisulfite was used to identify the microstructure. Metallographic observations at a magnification of $500 \times$ and $1000 \times$ were carried out with a Leica MEF 4A light microscope. Morphological details of microstructural constituents were revealed with the SUPRA 25 SEM using back-scattered electrons (BSE). Observations were performed on nital-etched samples at an accelerating voltage of $20 \mathrm{kV}$. Microhardness measurements were carried out across different areas using a Future-Tech FM-700 microhardness tester, by means of the Vickers method and applying a load of $1 \mathrm{~N}$ (HV0.1).

\section{Results and Discussion}

\subsection{Non-Metallic Inclusions}

The result of carrying out laser welding in an air atmosphere is a significant number of non-metallic inclusions formed in the fusion zone. Figure 1(a) presents a clear boundary between the fusion zone (FZ) and the heat-affected zone (HAZ). The distribution of inclusions is visible in an etched metallographic specimen (Fig. 1b), where the transitional zone (TZ) and base metal (BM) are also revealed. In the BM, the TZ and HAZ nonmetallic inclusions are arranged statistically randomly. A similar situation is in the fusion zone, where it is possible to observe uniformly arranged non-metallic inclusions, mainly of the globular form.

A detailed identification of non-metallic inclusions present in the base metal, HAZ, and fusion zone using EDS mapping was carried out (Ref 16). The base metal revealed the presence of sulfide or oxysulfide inclusions-globular or slightly elongated in the rolling direction. Due to the mischmetal addition during melting, the non-metallic inclusions are characterized by a modification of the chemical composition of the inclusions with rare-earth elements. Another type of nonmetallic inclusions can be observed in the fusion zone. Due to the high chemical affinity of $\mathrm{Al}$ and $\mathrm{Si}$ for oxygen, the inclusions are mainly of the oxide type. Al has higher affinity for oxygen than silicon. For this reason most inclusions are globular aluminum oxides, which is confirmed by an analysis of the chemical composition presented in Fig. 1(c) and carried out along line 1 , passing through the fusion zone. In the area where the inclusions are present (marked with circles in Fig. 1b) it is possible to observe clearly visible peaks coming from aluminum and oxygen. In addition, in Fig. 1(c) it is possible to observe a slightly lower Mn concentration in the fusion zone, which can probably be ascribed to partial manganese evaporation during the formation of a liquid metal pool. Similar oxide inclusions of random arrangement in the fusion zone were revealed by Amirthalingam et al. (Ref 15) in high-Al and high-Si TRIP steels. They also found that inclusions containing aluminum are greater in size than inclusions containing silicon, which is due to the higher temperature of $\mathrm{Al}_{2} \mathrm{O}_{2}$ formation. 

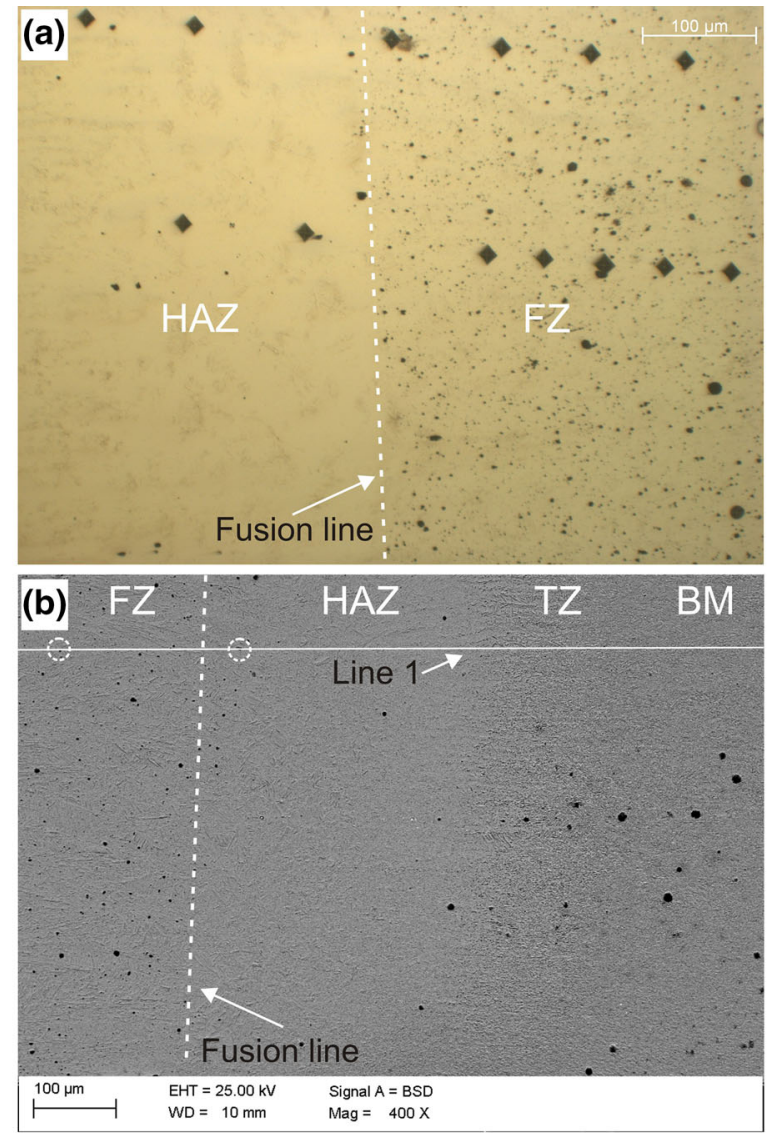

(c)

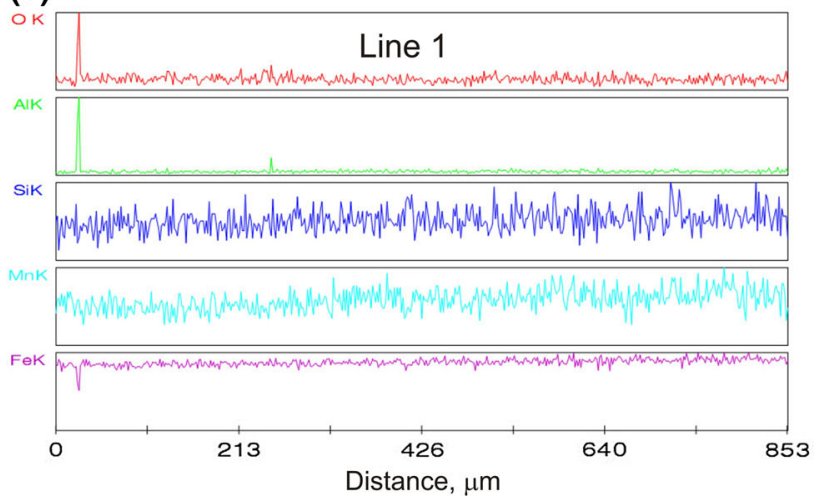

Fig. 1 Distribution of non-metallic inclusions in various sample zones of a non-etched (a) and etched metallographic specimen (b) and distribution of the concentration of individual elements along line 1 (c); the circles depict non-metallic inclusions intersected by line 1 and leading to a significant chemical composition change in Fig. 1(c)

The non-metallic inclusions are denser in the fusion zone even though they are smaller than those in the base metal (Fig. 1b). Sometimes, a large number of non-metallic inclusions can be the reason for hot brittleness of welds (Ref 17). This was not observed in the present study and in other TRIP steels (Ref 14, 15). The detrimental effect of non-metallic inclusions can also be revealed via decreasing plasticity of the welds. These investigations are in progress, and a more detailed analysis of the effects of revealed inclusions on welding quality can be found (Ref 16).

\subsection{Base Metal}

The matrix of the base metal contains $60 \%(\alpha)$ ferrite (Fig. 2a). Some ferrite grains are slightly elongated in the rolling direction. The ferritic matrix also contains bainiticaustenitic (B-A) islands of various sizes. Nital etching is insufficient to reveal retained austenite (Fig. 2a). This is possible only after using an aqueous solution of sodium metabisulfite (Fig. 2b).

A content of approximately $15 \%$ of retained austenite is present in three morphological forms. The largest blocky grains A (I) are present only on the boundary of the ferrite grains. Blocky grains A (II) are also frequently present on the boundary of ferrite and bainitic islands. The third morphological type with the highest mechanical stability (Ref 1,18$)$ is interlath retained austenite A (III) having varied thicknesses and located between the laths of bainitic ferrite (Fig. 2c). Such a bainitic microstructure with cementite replaced by layers of retained austenite is referred to as upper degenerate bainite (Ref 19, 20) and is a very good microstructural constituent of TRIP steels. On the other hand, the largest grains of $\gamma$-phase types (I) and (II), characterized by the lowest stability (Ref 2, 21), were partly transformed into martensite $(\mathrm{M})$ forming $\mathrm{M}-\mathrm{A}$ islands.

\subsection{Transitional Zone}

On the basis of previous initial tests it was possible to determine (Ref 13) that using heat input in a range between 0.037 and $0.053 \mathrm{~kJ} / \mathrm{mm}$ does not significantly affect the microstructure of FZ, HAZ, and $\mathrm{TZ}$ of the tested steel. In order to prevent excessive growth of austenite grains it is only necessary to limit the heat input below $0.045 \mathrm{~kJ} / \mathrm{mm}$. For this reason, the detailed microstructural characteristics were focused on the results obtained for the linear energy of $0.037 \mathrm{~kJ} / \mathrm{mm}$.

The transitional zone (TZ) is located directly near the base metal (BM). It is a part of the heat-affected zone. This region is most often defined as the intercritical heat-affected zone (ICHAZ) because the ICHAZ corresponds to the steel in the temperature range between $A_{c 1}$ and $A_{c 3}$. Due to the fine-grained microstructure of the steel it is difficult to identify individual constituents at a magnification of $500 \times$. However, it is easily possible to observe the location of the ICHAZ (Fig. 3a) and the increase in the amount of lath structural constituents toward the fine-grained heat-affected zone (FGHAZ). Higher magnification reveals a multiphase microstructure composed of ferrite $(\alpha)$ and lath bainitemartensite-austenite (B-M-A) areas (Fig. 3b). Precise determination of the microstructure becomes possible only after using magnification typical of SEM. On the basis of Fig. 3(c), it is possible to confirm the location of finegrained ferrite, laths of ferritic bainite (BF), and martensiticaustenitic (M-A) areas. Austenite is characterized by significantly greater resistance to the effect of the etchant than ferrite and bainite. For this reason it is revealed in the form of convex grains. The partitioning of carbon from ferrite to austenite in the range of intercritical temperatures favors stabilization of the $\gamma$-phase, the amount of which is significant in this zone.

The use of back-scattered electrons in SEM also makes it possible to distinguish local changes of the chemical composition as demonstrated by a slightly different image contrast. In the micrograph presented in Fig. 3(c), non-transformed austenite is revealed in the form of blocky grains or white laths. 

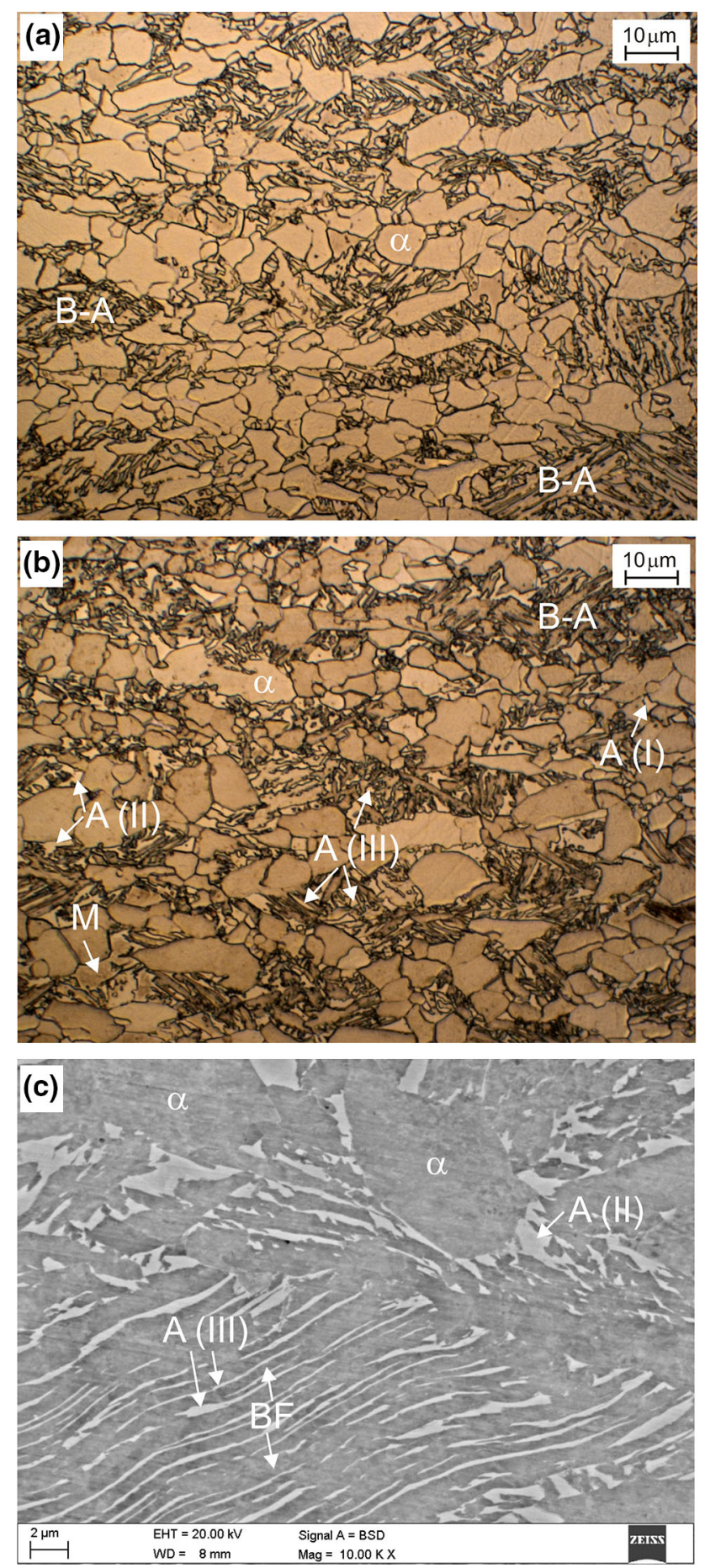

Fig. 2 Microstructure of the base metal composed of grains of a ferritic $(\alpha)$ matrix containing bainitic-austenitic (B-A) islands: (a) etching in nital, (b) etching in sodium metabisulfite, (c) SEM micrograph revealing bainitic ferrite (BF) laths and retained austenite on the boundary between ferrite and bainite A (II) and interlath retained austenite A (III)

However, it is possible to observe that most of the austenite has undergone a partial martensitic transformation and formed areas of the M-A type, which can have an adverse effect on the plasticity of the welded joints (Ref 22), similarly as is the case for non-metallic inclusions in the fusion zone. This issue will be a subject of further research. As regards plasticity of joints, it
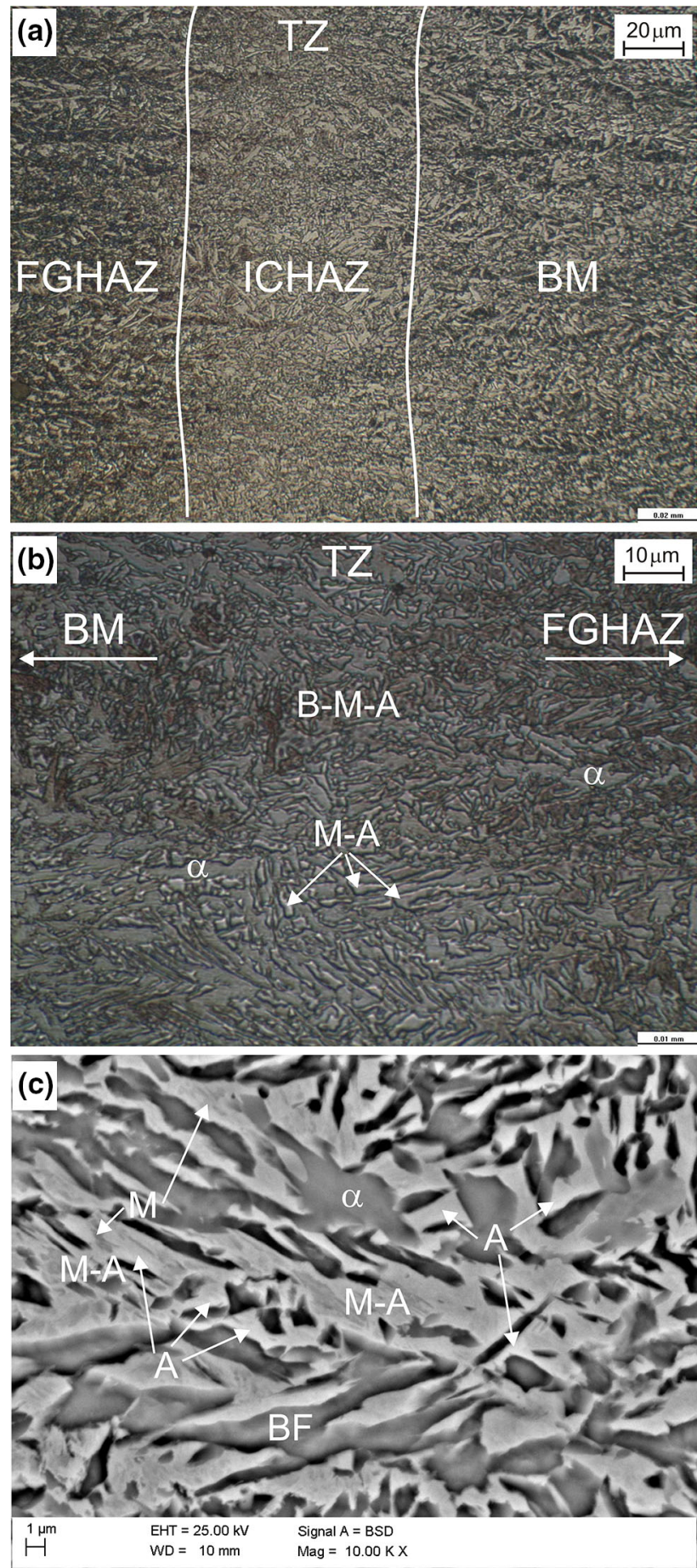

Fig. 3 Microstructure of the transitional zone revealed using LM (a) and (b), and SEM (c); B-M-A - bainite-martensite-austenite constituents, $\mathrm{M}-\mathrm{A}$ - martensite-austenite constituents, $\mathrm{BF}$ - bainitic ferrite, $\alpha$-ferrite, $\mathrm{A}$-retained austenite

seems that increasing the austenite/martensite ratio of the M-A areas brings positive effects. In relation to the microstructure, the stabilization of austenite requires increasing its carbon content, which entails applying, e.g., the bifocal welding technique or changing the laser beam focus. This should decrease the cooling rate and create the possibility of stabilizing a larger fraction of ductile retained austenite in the welded joint. 


\subsection{Heat-Affected Zone}

The essential part of the heat-affected zone (HAZ) corresponds to the temperature range between $A_{\mathrm{c} 3}$ and the fusion line. Generally, there are two HAZ regions above $A_{\mathrm{c} 3}$. Just above the $A_{\mathrm{c} 3}$ temperature is the fine-grained HAZ (FGHAZ). Grain growth in this region is limited due to the relatively lower temperature $\left(A_{\mathrm{c} 3} \sim 1200{ }^{\circ} \mathrm{C}\right)$. Another region corresponds to coarse-grained HAZ (CGHAZ). Grain growth is observed in the CGHAZ due to the higher temperature $\left(\sim 1200{ }^{\circ} \mathrm{C}\right.$-melting point $)$.

As can be seen in Fig. 4, there is a significant difference in grain size between the CGHAZ and FGHAZ. The region bordering with the ICHAZ is characterized by a fine-grained martensitic-bainitic microstructure (Fig. 4a, b). The size of the laths in the HAZ increases along with the decreasing distance from the fusion line, which is dependent on the heating temperature of steel during welding. Results obtained previously (Ref 13) showed that an increase in the heat input from 0.037 to $0.051 \mathrm{~kJ} / \mathrm{mm}$ led to a gradual increase in the HAZ width in a range from 0.32 to $0.45 \mathrm{~mm}$. The use of SEM allows revealing more precisely the bainitic-martensitic laths and, in particular, to reveal small particles and interlath retained austenite (Fig. 4c). The lack of ferrite and the related lack of austenite enriched with carbon are responsible for the insignificant fraction of the $\gamma$-phase.

\subsection{Fusion Zone}

In comparison with the HAZ, the type of microstructure in the fusion zone does not change, except for the different arrangement of martensitic-bainitic laths. Most lath areas are arranged in parallel to the direction of the fastest heat off-take (Fig. 5a). Additional characteristic elements of the fusion zone microstructure are numerous, globular, non-metallic oxide inclusions, the detailed characteristics of which are presented elsewhere (Ref 16). These inclusions are arranged randomly (Fig. 5b). The result of using back-scattered electrons creates the impression that these inclusions are pores (Fig. 5c). However, using this observation technique allows to better identify retained austenite due to a contrast revealing local changes in the chemical composition. It is difficult to detect retained austenite regions in the fusion zone. Kobayashi et al. (Ref 23) showed that retained austenite is fine and is located on the interlath boundary of the narrow martensite lath structure in 0.2C-1.5Mn-1.5Si TRIP steel. In the steel tested here this phase is present in the form of interlath retained austenite as well as fine blocky grains located on the boundaries of individual packages of martensitic-bainitic laths and on the boundaries of non-metallic inclusions (Fig. 5c).

Amirthalingam et al. (Ref 14) reported that the presence of soft ferrite at the fusion line in high-Al TRIP steels is possible as a result of aluminum partitioning to $\delta$-ferrite during solidification of the weld pool. In the steel tested here this phenomenon was not observed, as the concentration of aluminum was limited to $0.4 \%$. In spite of a high cooling rate, the fraction of retained austenite was initially assessed as an amount of a few percentage points. However, this requires more detailed research (in progress). This observation is consistent with results obtained by other authors (Ref 14, 15), who reported that the volume fraction of the thermally stable $\gamma$-phase in the weld amounts to between 6 and $9 \%$ depending on the TRIP steel grade (high-Si or high-Al concept) and the thermal history of the samples.
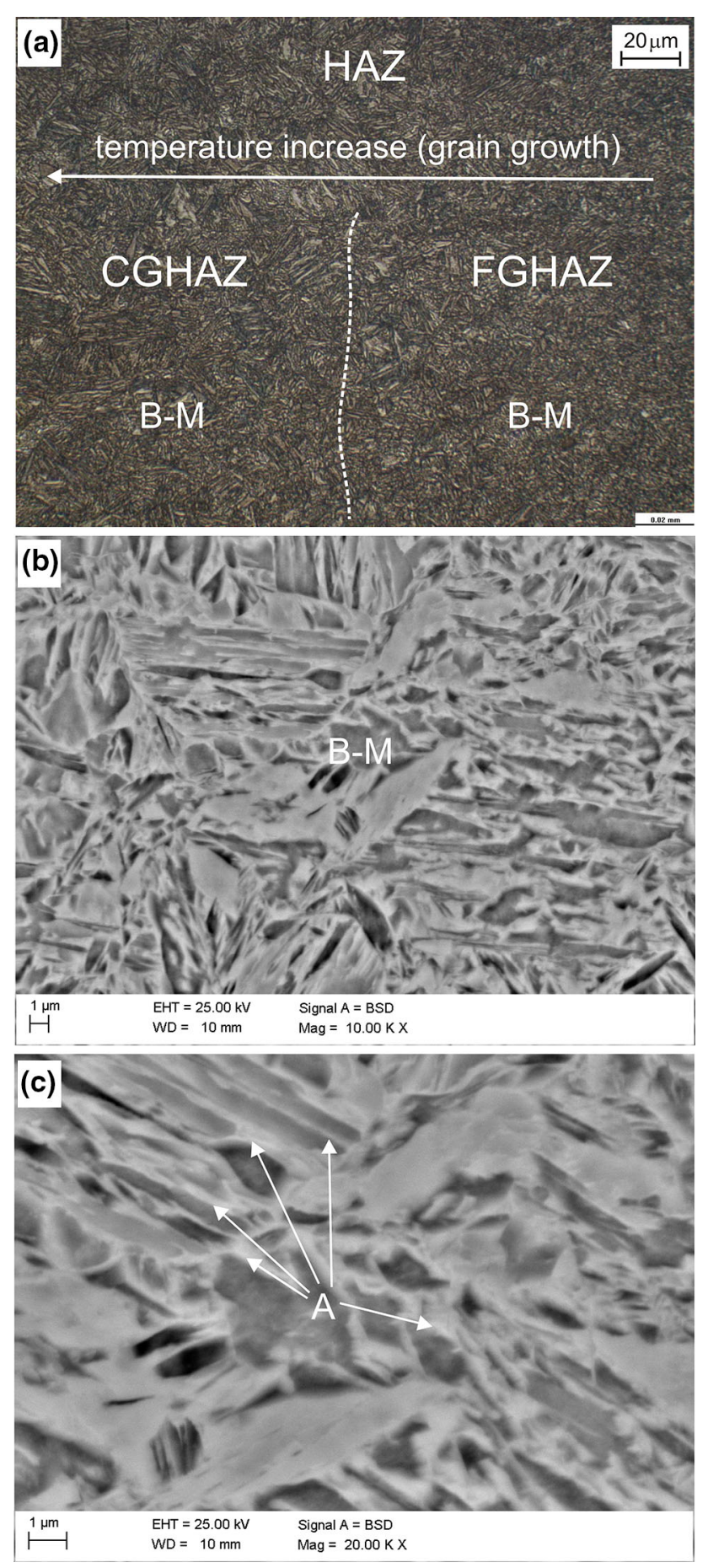

Fig. 4 Bainitic-martensitic microstructure of the heat-affected zone revealed using LM (a) and SEM (b), and small particles or interlath retained austenite (c); B-M-bainite-martensite constituents, Aretained austenite

\subsection{Microhardness Results}

The results of the microhardness measurements correspond well with the results of the microstructural tests. Figure 6 presents the microhardness of the samples welded at three heat input values $(0.037,0.043$, and $0.048 \mathrm{~kJ} / \mathrm{mm})$ measured at the center of the sheet thickness transverse to the weld line. According to the data, the change in the linear energy in the 

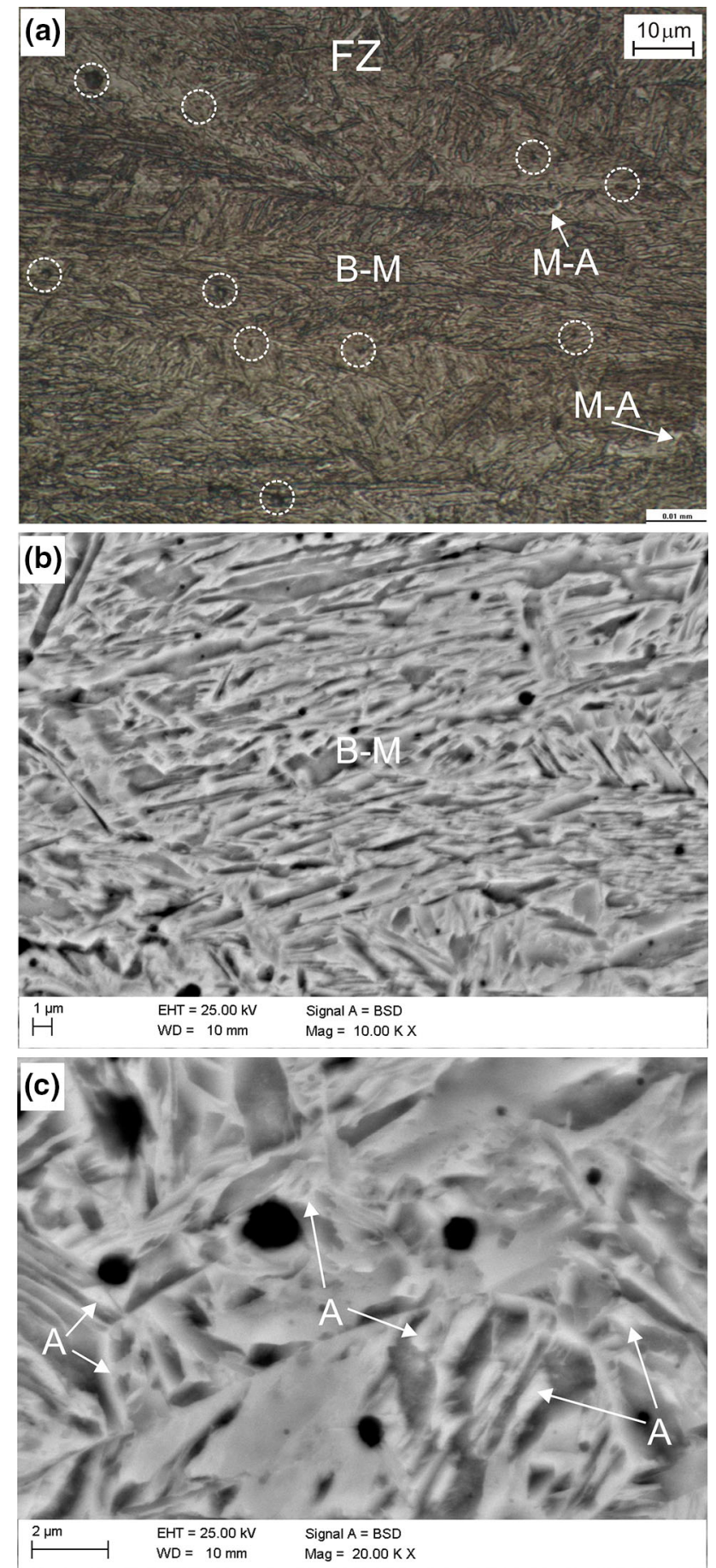

Fig. 5 Bainitic-martensitic microstructure of the fusion zone containing numerous non-metallic inclusions revealed using LM (a) and SEM (b), and small particles or interlath retained austenite and globular oxides (c); circles indicate non-metallic inclusions, B-M-bainite-martensite constituents, $\mathrm{M}-\mathrm{A}$-martensite-austenite constituents, A—retained austenite

range being analyzed does not affect the steel's microhardness or microstructure. According to data reported in (Ref 13), it is not possible to observe the scatter of microhardness on sheet thickness, which indicates homogeneity of the microstructure and the properties of a laser-welded joint. The average hardness of the base metal amounts to approximately $280 \mathrm{HV} 0.1$. On the curves it is possible to observe an increase in hardness from approximately 280 to $510 \mathrm{HV} 0.1$. This rise is related to the intercritical heat-affected zone (ICHAZ), where a ferrite fraction decreases gradually and, correspondingly, an increase in the fraction of lath bainitic-martensitic constituents takes place (Fig. 3).

The greatest hardness, i.e., 500-510 HV0.1, is present in the heat-affected zone. The HAZ has the highest hardness because it is usually the most affected by the highest residual stresses, especially if there is a high cooling rate (Ref 24). It is the combining effect of material inhomogeneity and thermal inhomogeneity that results in increased hardness. The peak in the hardness is present for fine-grained HAZ, where the fine martensitic-bainitic laths contribute significantly to its increase. In the coarse-grained HAZ there is a small decrease in hardness. More apparent is a further hardness decrease occurring in the fusion zone. In this region, microhardness decreases and stabilizes at a level between 450 and 490 HV0.1, independent of the heat input value that is applied. This behavior can be ascribed to the total dissolution of $\mathrm{Nb} / \mathrm{Ti}$ complex carbonitrides and a corresponding lack of the effect of precipitation strengthening. The hardness is nearly constant throughout the whole width of the weld. This is due to the homogeneous microstructure of the columnar grains in the fusion zone.

\section{Conclusions}

A detailed microstructure characterization of different weld regions of developed Nb-microalloyed TRIP-type steel with silicon partly replaced by aluminum is included. The result of the process, conducted in an air atmosphere, is the presence of numerous non-metallic inclusions of various sizes in the fusion zone. On the other hand, it is necessary to note that using a shielding gas significantly decreases the efficiency of laser welding and increases costs. The use of a remote welding technique, which is becoming increasingly more widespread in the automotive industry, would require the application of a shielding gas blowing system integrated with fitting accessories. Satisfactory weld quality is confirmed by the lack of HAZ softening, microcracks, and solidification cracking, which pose frequent problems during welding of thermomechanically rolled steel sheets. Further work is needed to assess weldability of the investigated steel. The base metal is characterized by a fine-grained ferritic-bainitic microstructure with a $15 \%$ fraction of retained austenite in the form of blocky grains and interlath retained austenite. A high cooling rate of the laser-welded joint fully determines the steel microstructure in the fusion zone and in the heat-affected zone. It is composed of lath martensiticbainitic constituents containing several percent of interlath retained austenite. Due to carbon enrichment of the austenite, the fraction of the $\gamma$-phase in the intercritical HAZ is close to its amount in the base metal. The welding linear energy, between 0.037 and $0.048 \mathrm{~kJ} / \mathrm{mm}$, has no effect on the microstructure and microhardness of steel, which shows the highest values up to $510 \mathrm{HV} 0.1$ in the fine-grained HAZ. 


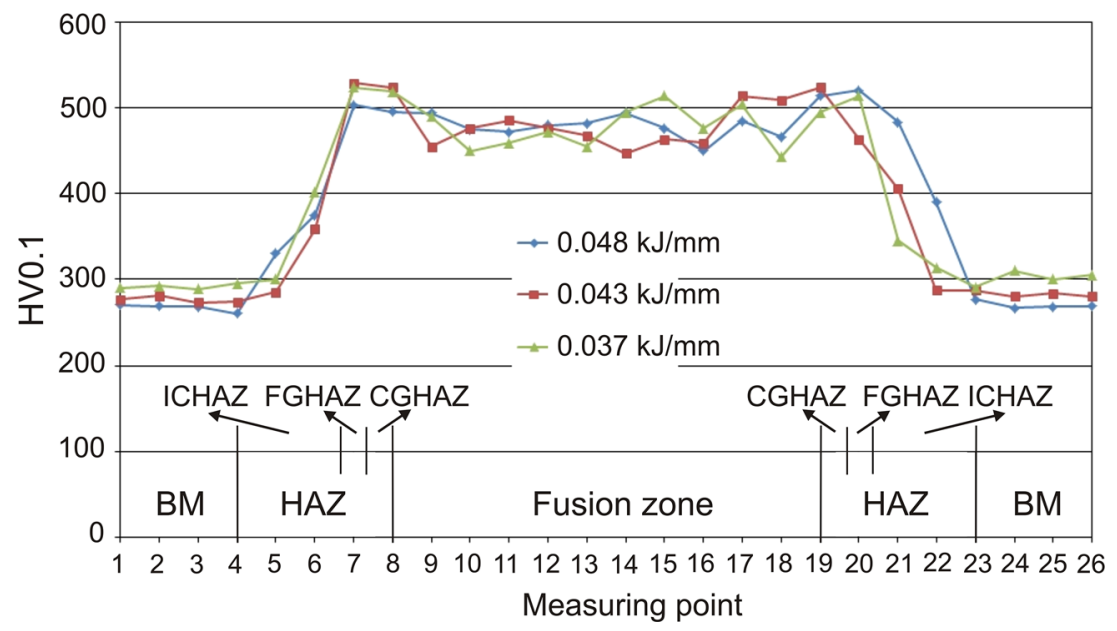

Fig. 6 Microhardness of the samples welded at various heat input values measured at the center of sheet thickness transverse to the weld line

\section{Open Access}

This article is distributed under the terms of the Creative Commons Attribution License which permits any use, distribution, and reproduction in any medium, provided the original author(s) and the source are credited.

\section{References}

1. D. Krizan and B.C. De Cooman, Analysis of the Strain-Induced Martensitic Transformation of Retained Austenite in Cold Rolled Micro-alloyed TRIP Steel, Steel Res. Int., 2008, 79(7), p 513-522

2. A. Grajcar, K. Radwanski, and H. Krzton, Microstructural Analysis of a Thermomechanically Processed Si-Al TRIP Steel Characterized by EBSD and X-Ray Techniques, Solid State Phenom., 2013, 203-204, p 34-37

3. S. Wiewiorowska, Determination of Content of Retained Austenite in Steels with TRIP Effect Deformed at Different Strain Rates, Steel Res. Int., 2010, 81, p 262-265

4. S. Traint, A. Pichler, R. Sierlinger, H. Pauli, and E.A. Werner, LowAlloyed TRIP-Steels with Optimized Strength, Forming and Welding Properties, Steel Res. Int., 2006, 77, p 641-649

5. L. Cretteur, A.I. Koruk, and L. Tosal-Martinez, Improvement of Weldability of TRIP Steels by Use of In-Situ Pre- and Post-heat Treatments, Steel Res., 2002, 73, p 314-319

6. S. Aslanlar, The Effect of Nucleus Size on Mechanical Properties in Electrical Resistance Spot Welding of Sheets Used in Automotive Industry, Mater. Des., 2006, 27, p 125-131

7. P. Burgmann, K. Clymer, S. Cobb, J. Davis, M. Liu, M. Miller, A. O'Loughlin, M. Smith, K.O. Findley, and S. Liu, Weldability, Processing, Microstructure and Mechanical Behavior Relationships in Advanced High-Strength Steel, Iron Steel Technol., 2010, 7, p 76-85

8. J. Senkara, Contemporary Car Body Steels for Automotive Industry and Technological Guidelines of Their Pressure Welding, Weld. Int., 2013, 3, p 184-189

9. Y.S. Yang and S.H. Lee, A Study on the Joining Strength of Laser Spot Welding for Automotive Applications, J. Mater. Process. Technol., 1999, 94, p 151-156

10. S. Stano, New Solid State Lasers and Their Application in Welding as Generators of Laser Radiation, Weld. Int., 2007, 3, p 809-813

11. A. Lisiecki, Diode Laser Welding of High Yield Steel, Proceedings of SPIE, Laser Technology 2012: Application of Lasers, Vol 8703, 2013, doi:10.1117/12.2013429
12. M.S. Weglowski, K. Kwiecinski, K. Krasnowski, and R. Jachym, Characteristics of Nd: YAG Laser Welded Joints of Dual Phase Steel, Arch. Civ. Mech. Eng., 2009, 9, p 85-97

13. A. Grajcar, M. Rozanski, S. Stano, A. Kowalski, and B. Grzegorczyk, Effect of Heat Input on Microstructure and Hardness Distribution of Laser Welded Si-Al TRIP-Type Steel, Adv. Mater. Sci. Eng., 2014, 2014, 8 pages, doi:10.1155/2014/658947

14. M. Amirthalingam, M.J.M. Hermans, L. Zhao, and I.M. Richardson, Quantitative Analysis of Microstructural Constituents in Welded Transformation Induced Plasticity Steels, Metall. Mater. Trans. A, 2010, 41, p 431-439

15. M. Amirthalingam, M.J.M. Hermans, and I.M. Richardson, Microstructural Development during Welding of Silicon and Aluminum Based Transformation Induced Plasticity Steels-Inclusion and Elemental Partitioning Analysis, Metall. Mater. Trans. A, 2009, 40, p 901-909

16. A. Grajcar, M. Rozanski, M. Kaminska, and B. Grzegorczyk, Study on Non-metallic Inclusions in Laser-Welded TRIP-Aided Nb-Microalloyed Steel, Arch. Metall. Mater., submitted for publication

17. B. Zorc, M. Imamovic, L. Kosec, B. Kosec, and A. Nagode, Influence of Non-metallic Inclusions on the Formation of Hot Cracks in the Weld and Heat-Affected Zone, Mater. Tehnol., 2014, 48(1), p 149-154

18. J. Wang and S. van der Zwaag, Stabilization Mechanisms of Retained Austenite in Transformation-Induced Plasticity Steel, Metall. Mater. Trans. A, 2001, 32, p 1527-1538

19. H.K.D.H. Bhadeshia, Bainite in Steels, The Institute of Materials, The University Press, Cambridge, 1992

20. S. Zajac, V. Schwinn, and K.H. Tacke, Characterisation and Quantification of Complex Bainitic Microstructures in High and Ultra-High Strength Linepipe Steels, Mater. Sci. Forum, 2005, 500-501, p 387-394

21. A. Kokosza and J. Pacyna, Mechanical Stability of Retained Austenite in Unalloyed Structural Steels of Various Carbon Content, Arch. Metall. Mater., 2010, 55(4), p 1001-1006

22. F. Matsuda, Y. Fukada, H. Okada, C. Shiga, K. Ikeuchi, Y. Horii, T. Shiwaku, and S. Suzuki, Review of Mechanical and Metallurgical Investigations of Martensite-Austenite Constituent in Welded Joints in Japan, Weld. World, 1996, 37, p 134-154

23. J. Kobayashi, S.M. Song, and K. Sugimoto, Microstructure and Retained Austenite Characteristics of Ultra High-Strength TRIP-Aided Martensitic Steels, ISIJ Int., 2012, 52(6), p 1124-1129

24. P. Mabelly, P. Bourges, and G. Pont, Effect of Metallurgical Transformations on Weld Residual Stresses-Application to E690 Steel Grade, Mar. Struct., 2001, 14, p 553-567 